\title{
Introduction to the Topical Issue on Nuclear Explosion Monitoring and Verification: Scientific and Technological Advances
}

\author{
Martin B. Kalinowski ${ }^{1}$ and Pierick Mialle ${ }^{1}$
}

The Comprehensive Nuclear-Test-Ban Treaty (CTBT) has been negotiated at the Conference on Disarmament in Geneva between 1993 and 1996. It was opened for signature in September 1996. Though the CTBT has been signed by 185 states and ratified by 170 (as of 2021), it is not yet in force due to its specific conditions for entry-into-force. However, the Preparatory Commission for the CTBT Organisation has a mandate to establish the International Monitoring System (IMS), the International Data Centre (IDC) and prepare the procedures for On-Site Inspections (OSI). This is carried out by the Provisional Technical Secretariat (PTS) based in Vienna, Austria. The goal is to have the completed verification system in place and ready to operate as soon as the CTBT enters into force.

The CTBT has several provisions for verification of compliance. The IMS consists of four networks with different sensor technologies: seismic, hydroacoustic, infrasound and radionuclides. In addition, the CTBT allows for confidence building measures, consultation and clarification as well as OSI.

The purpose of the IMS sensor network is to detect signals that are indicative of nuclear explosions, as well as to identify and to locate nuclear explosions underground, underwater or in the atmosphere. Upon completion, the IMS network will consist of 337 facilities in order to monitor the whole geosphere. These are 321 stations and 16 radionuclide

The views expressed in this introduction paper and in the contributions to this topical volume are those of the authors and do not necessarily reflect the views of the CTBTO nor of the organizations that the authors represent.

1 Preparatory Commission for the Comprehensive NuclearTest-Ban-Treaty Organization, Provisional Technical Secretariat, Vienna International Centre, P.O. Box 1200, 1400 Vienna, Austria. E-mail: martin.kalinowski@ctbto.org laboratories. As of March 2021, 302 of these have already been certified, 9 more are installed and 5 are under construction. The seismic network consists of 50 primary and 120 auxiliary seismological stations to monitor primarily the solid Earth; the hydroacoustic network comprises 11 stations, 6 hydrophone stations and 5 island or coastal seismic T-phase station to monitor primarily the oceans; 60 infrasound stations to survey the atmosphere and 80 radionuclide stations to identify the "smoking gun" relevant to confirm a possible violation of the CTBT (Hoffmann et al., 1999).

The almost completed IMS collects on a regular basis waveform (seismic, hydroacoustic, infrasound) and radionuclide data and the IDC does the data analysis and creates products on a daily basis. Whereas the purpose of these four sensor networks is for verifying compliance with the CTBT, the raw data can be used for a broad range of civil and scientific applications. Their use by the scientific community brings back additional expertise and research and development that are of benefit for nuclear explosion monitoring.

On-site verification can only be conducted after entry into force of the CTBT. In preparation for this, the technical capabilities are developed and tested. Surrogate inspectors are nominated by States Signatories and trained. The technological capabilities are tested in Build-Up Exercises and Field Tests.

In all sensor technologies and relevant scientific disciplines, significant advances in nuclear explosion monitoring were recently achieved. This progress in the development and testing of new methods improves the capabilities in detection, location, and characterization of CTBT relevant events. In particular the latter poses a challenge for smaller events, 
where natural or manmade-but CTBT irrelevantsources can generate false positive events. The efficient discrimination of these events pursued at a minimum risk of missing a relevant event is the overall challenge.

The CTBTO Preparatory Commission (PrepCom) undertakes special endeavours to ensure that the complete verification system from sensor technology to analysis algorithms is state-of-the-art. The international scientific community is instrumental in achieving the goal of constant improvement of the verification regime. Scientists drive the relevant research and technical innovations that may shape the future of nuclear explosion monitoring and technical readiness for on-site inspections. ${ }^{1}$

Many technical workshops are organised every year by the CTBTO. An important opportunity for interaction with the broader scientific community is the CTBT: Science and Technology (SnT) Conference series at the Hofburg palace in Vienna. Since 2011, it takes place every 2 years (CTBTO, 2011, 2013, 2015, 2017, 2019). Prior to the SnT conference series, the scientific symposium on "CTBT: Synergies with Science 1996-2006 and beyond" (CTBTO, 2006) and the International Scientific Studies (ISS) Conference (CTBTO, 2009) were conducted.

Another platform to instigate a dialogue with the scientific community on research relevant to nuclear explosion monitoring is the annual General Assembly of the European Geosciences Union (EGU) that is convened yearly during springtime in Vienna. Since 2007, a special session on "Research and Development in Nuclear Explosion Monitoring", renamed in 2018 to "International Monitoring System and Onsite Verification for the CTBT, disaster risk reduction and Earth sciences". The papers presented in the first two special sessions formed the basis for the topical volume of Pure and Applied Geophysics, "Recent

\footnotetext{
${ }^{1}$ According to Article IV, 11 of the CTBT "Each State Party undertakes to cooperate with the Organization and with other States Parties in the improvement of the verification regime, and in the examination of the verification potential of additional monitoring technologies such as electromagnetic pulse monitoring or satellite monitoring, with a view to developing, when appropriate, specific measures to enhance the efficient and cost-effective verification of this Treaty".
}

Advances in Nuclear Explosion Monitoring" (PAGEOPH, 2010). The compilation of the second topical volume on "Recent Advances in Nuclear Explosion Monitoring" results from a call for papers (PAGEOPH, 2014). Many of these papers were originally presented at the annual General Assemblies of the EGU.

These two volumes can be considered a follow-up to research published in a series of topical volumes in Pure and Applied Geophysics in the years 2001-2002, with Brian Mitchel acting as the main editor of that series (PAGEOPH, 2001a, b, c, d, e; PAGEOPH, 2002a, b) following the opening for signature of the CTBT in 1996.

Selected authors to the CTBT: Science and Technology 2019 Conference (SnT2019) were invited to submit their contribution as full paper for this topical issue of Pure and Applied Geophysics (PAGEOPH). The SnT2019 Conference had the following five themes: (1) The Earth as a complex system, (2) events and nuclear test sites, (3) verification technologies and technique applications, (4) performance optimization, and (5) CTBT in a global context. Half of the 20 papers of this volume are in the waveform domain and the other half in the field of nuclear measurement technologies. One of the manuscripts in the latter group integrates radionuclide and infrasound measurements. Most papers relate to IMS data and IDC products and two papers are relevant for OSI.

The first paper of the volume focuses on discrimination between anthropogenic activity, and specifically explosive events, and natural seismicity by application of a machine learning technique called diffusion maps. The novelty in this study is the extension of the technique on data from seismic arrays, and the demonstration of improved discrimination performance on data from the IMS seismic array of Mount Meron (MMAI), Israel.

The treaty monitoring community continuously seeks ideas to better detect, locate and discriminate with the objective to optimize detection capability of the IMS. It is thus needed to understand the performance of the IMS and each of its components. Here a paper focuses on the seismic detection capabilities by using a method based on measurements of ambient seismic noise at seismic stations, both primary and 
auxiliary, with corrections of body wave magnitudes. Network capability performance estimates are compared with Reviewed Event Bulletin (REB) results.

With its continuous objective to improve its algorithm, the IDC embarked on a ten-year long journey to design an improved alternative to its legacy network processing software, Global Association (GA), which performs automatic associations for seismic, hydroacoustic and infrasound technology. This new software, NET-VISA, reached maturity for all three waveform technologies and it is incorporated in IDC operational system to demonstrate the achieved performance improvements.

High quality and complete detection catalogues are essential to network processing, hence another area of interest for the seismic treaty monitoring community is the ability to lower the threshold of signal detection. This is especially critical given the sparsity of the IMS seismic network, which motivates researchers to make best use of data from single stations of the IMS. In this work, a deep neural network method is applied to multiple years of data from a selection of IMS three-component stations in an attempt to improve accuracy of backazimuth predictions.

After two decades of operational use, another part of the IDC system for seismic technology is considered for replacement with a novel approach, IDC source-specific station corrections (SSSC). Two papers in this volume present the Regional Seismic Travel Time (RSTT) model, which was developed to improve travel-time prediction accuracy by accounting for three-dimensional crust and upper mantle structure. They focus on two key aspects, the tomographic inversion and the path dependent travel-time uncertainties. While both papers are closely related, the second part is not included in this topical volume; and already published as Begnaud et al. (2021).

Moving towards the hydro-acoustic technology, two papers present in this volume review the loss of the Argentinian ARA San Juan military submarine that occurred on 15 November 2017. Both papers build on the 15 November signals of unknown origin and the December 1st calibration explosion detected by two hydrophone stations part of the IMS network. They illustrate on one hand the methodologies applied by CTBTO for the detection, localization and characterization, and on the other hand novel techniques for refining detection results and for relocation with improved accuracy.

Still in the domain of hydro-acoustic technology, another paper focuses on specificities of the island or coastal seismic stations of the IMS named T-phase stations. The challenge at hand is the scarcity of signals of interest identified in data from T-stations due to the inefficient, and poorly understood, conversion of the hydroacoustic to seismic signal at the interface between ocean and land. The study makes use of numerical computations with a spectral element method to assist the signal characterization of waves recorded at T-stations.

The next paper brings the reader to the atmosphere and the need for modelling techniques describing accurately long-range propagation of infrasound waves in the atmosphere. While the propagation effect of the fine-scale structure of the stratosphere have gathered a lot of attention in recent years, the impact of thin layers on propagation and particularly of a stable Atmospheric Boundary Layer (ABL) is not well understood. This study demonstrates the similarity of long-range propagation in a shallow tropospheric waveguide with long range stratospheric and thermospheric propagation, which can be observed during controlled surface explosion campaigns.

Data fusion of the three waveform sensor technologies (seismic, hydroacoustic, infrasound) is common practise. The joint analysis of an event with both radionuclide and waveform technologies is less often accomplished and an active research and development area. The study on the volcanic activity of Bogoslof in Alaska, USA, is used as an opportunity to investigate the synergy between radionuclide and infrasound observations by using atmospheric transport modelling simulations.

This volume contains a paper on the detectability of ${ }^{133} \mathrm{Xe}$ emissions from a hypothetical nuclear test at the location of the DPRK test site Punggye-ri. The authors assess the sensitivity of the IMS radionuclide station at Takasaki, Japan, to emissions of radioxenon from selected locations in the region of the Korean peninsula. This study highlights the challenge of distinguishing a possible nuclear explosion signal 
from different known sources to explain observed ${ }^{133} \mathrm{Xe}$ concentrations.

The challenge of interferences from global radioxenon background that are caused by naturally occurring and man-made radionuclides is one of the most important problems for the worldwide nuclear explosion monitoring. A review paper summarizes the state-of-the art of the relevant scientific work in characterizing the radioxenon background in the atmosphere and discusses possible mitigation strategies and next steps in support of nuclear explosion detection.

Another paper illustrates the importance of detailed knowledge of radioxenon emissions from nuclear power plants when interpreting radioxenon measurements for nuclear test ban verification. It uses 3 years of stack data recording the radioxenon releases from a nuclear power plant and applies atmospheric transport modelling to relate them with atmospheric measurements made in Stockholm made with a sensitive radioxenon detection system.

Since enhancing the knowledge about known sources of radioxenon emissions is crucial for effective nuclear explosion monitoring, two papers contribute to the establishment of a global radioxenon emission inventory. The first one presents an update of annual radioxenon releases from all nuclear power plants worldwide by incorporating all publicly available reported emissions for a specific year rather than using generic estimates. This is important because the emissions from the same source may vary by many orders of magnitude from one year to another. The second paper is the first attempt ever made to explore the global radioxenon emissions from the global fleet of nuclear research reactors. This is difficult due to the sparse number of reported release measurements and the large technical variety of reactor designs and operational conditions. As a result, this study demonstrates that some nuclear research reactors can have an impact on IMS radioxenon systems.

The IMS radionuclide stations are supplemented by 16 radionuclide laboratories. The purpose of these laboratories is quality control and validation of measurements made at the IMS stations. A subset of these laboratories has radioxenon measurement capabilities. One of them is the U.S. Radionuclide
Laboratory. Its design and operation are described in a paper of this topical volume. The authors concluded that improved laboratory performance could allow for the better characterization of radioxenon backgrounds at IMS stations.

From time to time, it is suggested that the detection of antineutrinos emitted from a nuclear test explosion could be used as a supplementary approach to IMS sensors for nuclear explosion monitoring. A careful study reviews several hypothetical use cases for antineutrino detectors and comes to the conclusions that this remains impractical. In each case, if an anti-neutrino detector could be constructed that would compete with existing capabilities, the authors conclude that the cost would considerably outstrip the value it might add to the existing monitoring network.

In case of an OSI that would be possible after entry into force of the CTBT, radionuclide measurements would be done by inspectors in the field. Besides of certain particulate-born radioisotopes and radioxenon, also ${ }^{37} \mathrm{Ar}$ is relevant for OSI. In this topical volume, a high throughput field system is presented. The authors describe in detail the whole system design and the extensive testing that it has undergone against rigorous requirements to assure the system meets the needs of the OSI noble gas measurements.

Aerial radiometric survey is an efficient means for OSI to cover large areas. The last paper of this topical volume introduces the Advanced Radiation Detector for Unmanned Aerial Vehicle (UAV) Operations (ARDUO) and investigates its possible contribution to OSI. Its specific strength is that the gamma spectrometer is direction capable. It can point out the direction toward a source of radioactivity while in flight and it can be used for perimeter survey and view into areas that are declared by the inspected state party as sites of restricted access to the inspectors.

In summary, this topical volume achieves a good distribution of papers across all areas of CTBT verification. For the full picture of all 342 posters and 120 oral presentations made at the SnT2019, the reader is recommended to read the detailed conference report (CTBTO, 2020). In chapter 6, that report summarizes the relevance to CTBTO activities and 
verification science that can be inferred from the presentations made at SnT2019.

The guest editors hope that the wealth of the information given in this volume will prove a useful reference for future research in nuclear explosion verification.

\section{Acknowledgements}

We are grateful for the contributions from all authors and the helpful and constructive advices received from reviewers. We would also like to express our appreciation to the publisher, Springer/Birkhäuser.

Open Access This article is licensed under a Creative Commons Attribution 4.0 International License, which permits use, sharing, adaptation, distribution and reproduction in any medium or format, as long as you give appropriate credit to the original author(s) and the source, provide a link to the Creative Commons licence, and indicate if changes were made. The images or other third party material in this article are included in the article's Creative Commons licence, unless indicated otherwise in a credit line to the material. If material is not included in the article's Creative Commons licence and your intended use is not permitted by statutory regulation or exceeds the permitted use, you will need to obtain permission directly from the copyright holder. To view a copy of this licence, visit http://creativecommons.org/licenses/by/4. $0 /$.

Publisher's Note Springer Nature remains neutral with regard to jurisdictional claims in published maps and institutional affiliations.

\section{REFERENCES}

Begnaud, M. L., Anderson, D. N., Myers, S. C., Young, B., Hipp, J. R., \& Phillips, W. S. (2021). Updates to the regional seismic travel time (RSTT) Model: 2. Path-dependent travel-time uncertainty. Pure and Applied Geophysics, 178(2), 313-339.

CTBTO. (2006). CTBT: synergies with science 1996-2006 and beyond symposium. http://www.ctbto.org/specials/ctbtsynergies-with-science1996-2006-and-beyond/. Accessed 5 July 2021.
CTBTO. (2009). International Scientific Studies (ISS) Conference. http://www.ctbto.org/specials/the-international-scientific-studiesproject-iss/. Accessed 5 July 2021.

CTBTO. (2011). CTBT Science and Technology Conference 2011. http://www.ctbto.org/?id=2538. Accessed 5 July 2021.

CTBTO. (2013). CTBT Science and Technology Conference 2013. http://www.ctbto.org/specials/snt2013/. Accessed 5 July 2021.

CTBTO. (2015). CTBT Science and Technology Conference 2015. https://www.ctbto.org/specials/snt2015/. Accessed 5 July 2021.

CTBTO. (2017). CTBT Science and Technology Conference 2017. https://www.ctbto.org/specials/snt2017/. Accessed 5 July 2021.

CTBTO. (2019). CTBT Science and Technology Conference 2019. https://events.ctbto.org/snt/snt2019/. Accessed 5 July 2021.

CTBTO. (2020). Scientific advances in CTBT monitoring and verification 2019. In Review of presentations and outcomes of the Comprehensive Nuclear-Test-Ban Treaty: science and technology 2019 conference, 24-28 June 2019, Hofburg Palace, Vienna. https://events.ctbto.org/sites/default/files/2020-08/SnT2019repo rt_published.pdf. Accessed 5 July 2021.

Hoffmann, W., Kebeasy, R., \& Firbas, P. (1999). Introduction to the verification regime of the Comprehensive Nuclear-Test-Ban Treaty. Physics of the Earth and Planetary Interiors, 113, 5-9.

PAGEOPH. (2001a). Monitoring the Comprehensive Nuclear-TestBan Treaty: source location, (F. Ringdal, \& B. L. N. Kennett (Eds.)). Pure Applied Geophysics 158(1/2)

PAGEOPH. (2001b). Monitoring the Comprehensive Nuclear-TestBan Treaty: hydroacoustics, (C. deGroot-Hedlin, \& J. Orcutt (Eds.)). Pure Applied Geophysics 158(3)

PAGEOPH. (2001c). Monitoring the Comprehensive Nuclear-TestBan Treaty: regional wave propagation and crustal structure, $(\mathrm{H}$. J. Patton, \& B. J. Mitchell (Eds.)). Pure Applied Geophysics 158(7)

PAGEOPH. (2001d). Monitoring the Comprehensive Nuclear-TestBan Treaty: surface waves (A. L. Levshin, \& M. H. Ritzwoller (Eds.)). Pure Applied Geophysics 158(8)

PAGEOPH. (2001e). Monitoring the Comprehensive Nuclear-TestBan Treaty: source processes and explosion yield estimation, (G. Ekström, M. Denny, \& J. R. Murphy (Eds.)). Pure Applied Geophysics 158(11)

PAGEOPH. (2002a). Monitoring the Comprehensive Nuclear-TestBan Treaty: seismic event discrimination and identification, (W. R. Walter, \& H. E. Hartse (Eds.)). Pure Applied Geophysics 159(4)

PAGEOPH. (2002b). Monitoring the Comprehensive Nuclear-TestBan Treaty: data processing and infrasound, (Z. A. Der, R. H. Shumway, \& E. T. Herrin (Eds.)). Pure Applied Geophysics 159(5)

PAGEOPH. (2010). Recent advances in nuclear explosion monitoring, (A. Becker, B. Schurr, M. B. Kalinowski, K. Koch, \& D. Brown (Eds.)). Pure Applied Geophysics 167(4-5)

PAGEOPH. (2014). Recent advances in nuclear explosion monitoring, (M.B. Kalinowski, \& A. Becker (Eds.)). Pure Applied Geophysics 171(3) 